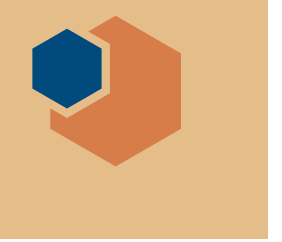

\title{
US visa problems amid COVID-19 disrupt materials research
}

$\mathrm{D}$ ue to high unemployment in the United States owing to the economic fallout of the coronavirus pandemic, non-US citizens have been experiencing a bumpy ride this summer when it comes to plans for working or studying in the country.

The Trump administration has restricted work visas through the end of 2020, with the possibility of continuing the constraint into 2021. This also pertains to non-US citizens who were outside the country at the time the proclamation was made on June 22, 2020. The visas affected are $\mathrm{H}-1 \mathrm{~B}, \mathrm{H}-2 \mathrm{~B}, \mathrm{~J}$, and $\mathrm{H}$, applying to non-US workers and exchange visitors.

"I came back to China last year to attend my grandpa's funeral. Then I went to refresh my J-1 visa, but haven't been hearing back since then," says a materials researcher who has held a postdoctoral position at a university in the United States. He agreed to speak to MRS Bulletin on condition of anonymity.
"I have to ask my mom-who has an effective visa - to help me deal with my house, cars, etc. in the US," he says. "I really don't understand why the US did this to us." The postdoctoral candidate works on synthesis of two-dimensional (2D) materials and applications in energy storage, 2D magnets, and the terahertz field.

To further exacerbate the research environment, the Student and Exchange Visitor Program (SEVP) that falls under the auspices of the US Immigration and Customs Enforcement, or ICE, limited the ability of students to attend university on an F-1 nonimmigrant student visa unless they attend in-person classes in the Fall semester, as per an ICE announcement on July 7, 2020. Such a stipulation would be difficult to fulfill in major US universities such as the Massachusetts Institute of Technology (MIT) and Harvard University who plan to offer most of their courses online for the safety of students and faculty during the pandemic.

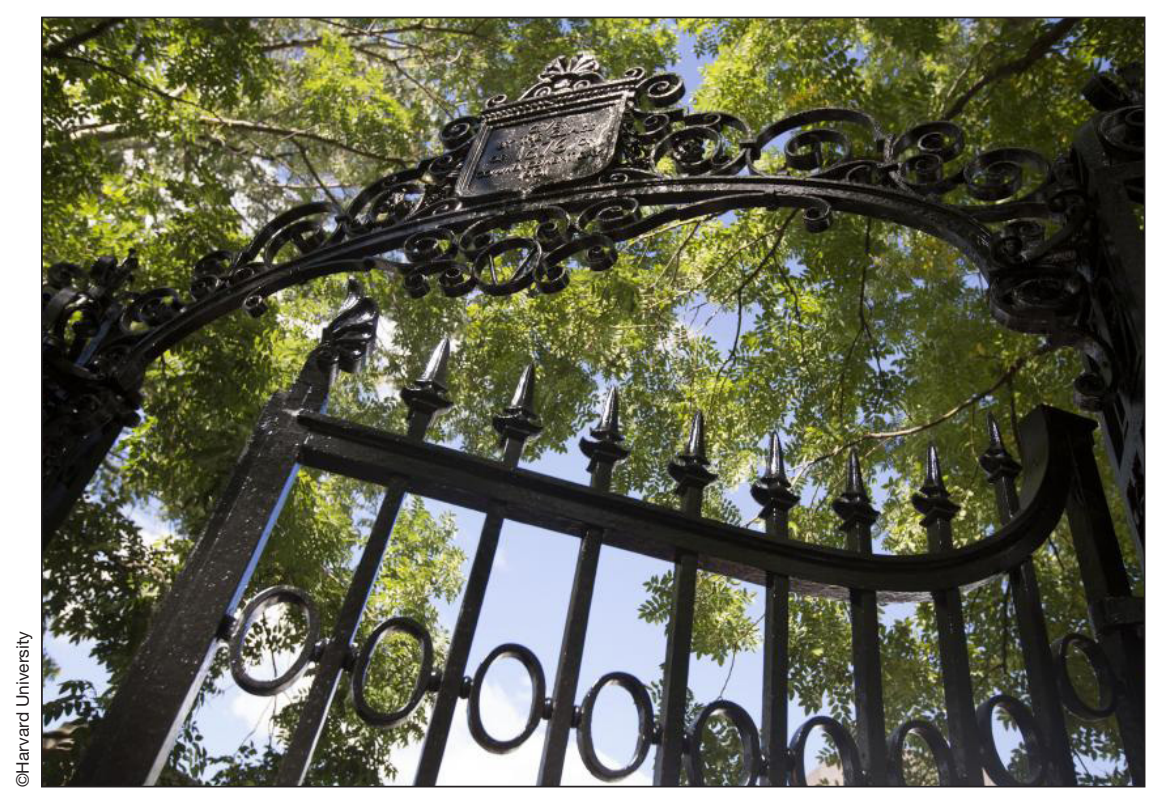

Then within just eight days, the Trump administration rescinded the SEVP restrictions, as reported for example by the Boston Herald, "I have been informed by the parties that they have come to a resolution,' US District Judge Allison Burroughs said during a Tuesday hearing." The hearing refers to a lawsuit filed on July 8 by MIT and Harvard for a temporary restraining order and ultimately setting aside the restriction.

The two Boston institutions were not alone. On July 13, 2020, 18 states-led by Massachusetts Attorney General Maura Healey - filed a suit against the directive, and before that, coalitions advocating for science and technology had sent letters to Capitol Hill. The Materials Research Society (MRS) has also signed onto a multi-society letter.

"When it comes to immigration issues we tend to work inside of our coalitions," says Damon Dozier, Director of Government Affairs for MRS. These coalitions, he says, include the Coalition for National Science Funding and the Task Force on American Innovation.

In addition to the multi-society letter, MRS President Matt Copel sent a letter on behalf of the Society to the US president. The restriction on international students, Copel wrote, "will severely harm the ability of the US to recruit and maintain intellectual talent and to perform at academic institutions." Copel appealed to the financial distress the directive would impose on both international students and institutes of higher learning.

"The new guidance," Copel writes, "while pitched as a public health protective measure ... is contrary to established scientific evidence regarding pandemic infection control." A copy of the letter also went to the Department of State, Department of Homeland Security, and the Science and Technology Adviser. 
Copel and Dozier both expressed surprise when the student visa restriction was rescinded. "I'll be honest with you," Dozier tells MRS Bulletin, "I was surprised ... it was announced on Monday, and by the next [Tuesday] it was gone."

"Given how suddenly policy changes are happening, I guess I should not have been surprised," Copel says. "It would be wonderful if this could mark the beginning of a sensible policy toward the visa program."

However, while the materials research community in the United States may continue to welcome international students to its academic programs, visas for postdoctoral fellows and researchers remain a problem. "There is a general sense of deep concern about the negative impact, both direct and indirect, that such antiimmigration policies will have on the quality of science and technology in the US," says Amit Misra, chair of the
Materials Science \& Engineering Department at the University of Michigan, and chair of the MRS Bulletin Editorial Board.

Yuchi Cui, who returned to China after receiving his $\mathrm{PhD}$ degree from the University of Michigan in April this year, tells MRS Bulletin, "My original plan was to come back in June or July and take a postdoc position in my advisor Professor Misra's group. Unfortunately, due to the travel ban and the shutdown of the US Embassy in China, I do not see this happening anytime soon."

Cui works in high-performance metallic materials. "We had a project halfway finished before I left, which just needs a few more experiments. I'm not sure if anyone in our group will take on the work, as I was the only one who knew the recipe to make the sample and do the tests," Cui says.

The visa suspension affects industry as well, according to Copel who works at the IBM T.J. Watson Research Center. "In industry, their objective is to get the best talent they can find in the world." In another letter sent to the Trump administration on behalf of MRS, Copel notes that this "action will have a deleterious impact on the US science and engineering output, causing harm to the American scientific enterprise."

Frustrated staying at home, not knowing whether he will be able to return to the United States, Cui has started thinking about getting a research job in China.

And the postdoctoral research fellow, speaking on condition of anonymity, had accepted a professorship in China. However, he tells MRS Bulletin, "apparently it's difficult to collaborate with my colleagues in the US now."

"Politics cannot impede the development of science and technology; this is the bottom line!' he says.

Judy Meiksin

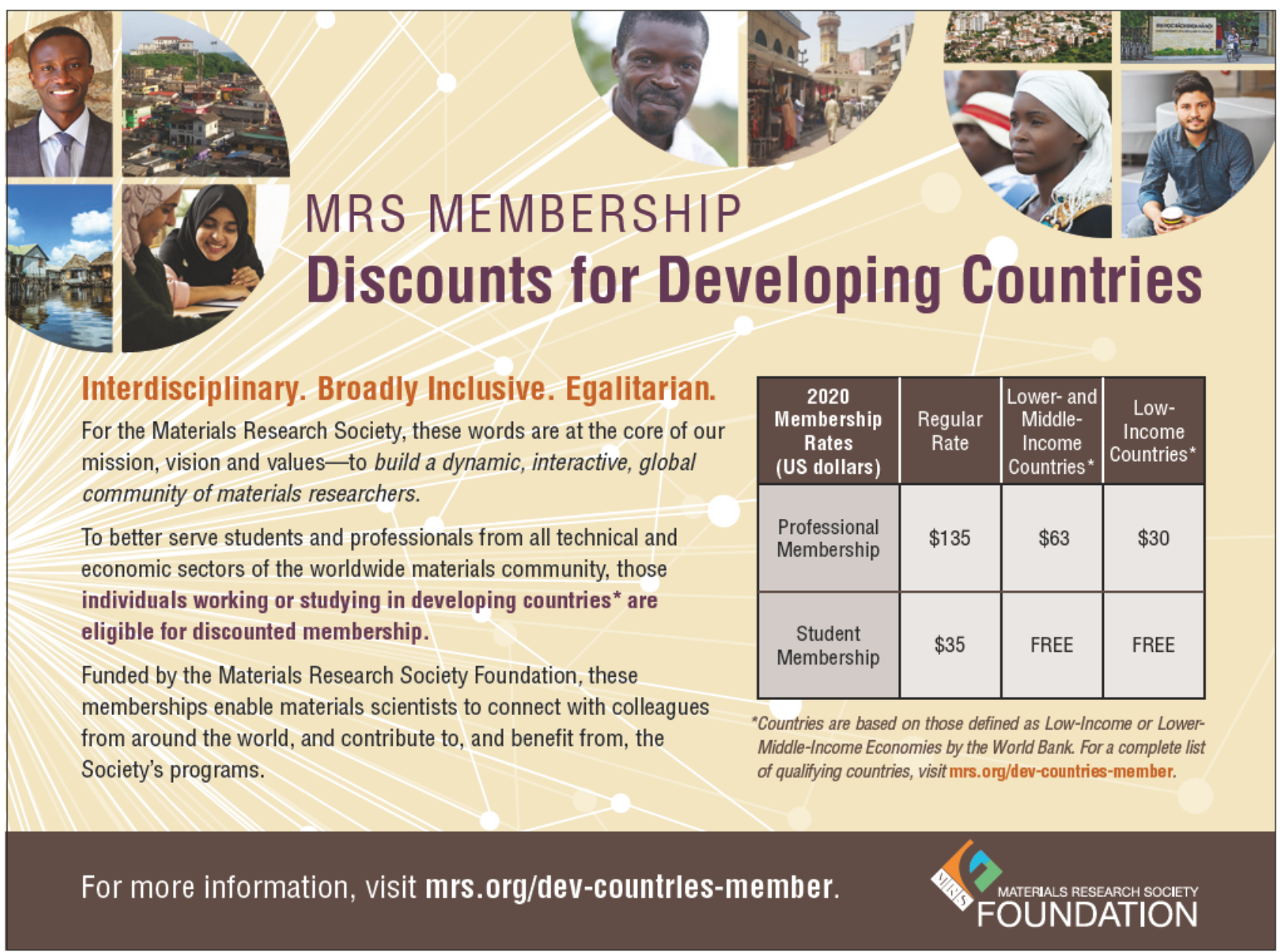

